\title{
NPM AND PERFORMANCE MEASUREMENT: A COMPARATIVE STUDY OF THE PUBLIC SECTORS IN IRELAND AND THE UK
}

\author{
Noel Hyndman \\ Queen's University Belfast \\ and \\ Francis McGeough \\ Institute of Technology Blanchardstown
}

\begin{abstract}
The use of quantitative, often non-financial, targets and performance measures by businesses and not-for-profit organisations has recently received increasing attention in the academic literature. In the public sector this has been particularly driven by the rise and influence of New Public Management (NPM), resulting in a shift from issues of policy to issues of management, and the break-up of traditional bureaucratic structures. One aspect of these changes is an increasing focus on quantitative measures of performance as a support for better decision making and more appropriate accountability in the public sector. Driven by the NPM agenda, public sector organisations have sought to develop targets that cover all aspects of an organisation's performance. However, the extent to which such an agenda and focus has impacted varies between countries. This paper seeks to examine the possible role of quantitative targets and measures in public sector organisations in general and, through an exploratory study of annual reports, the nature and breadth of the usage of targets and measures are examined in a comparative study of Ireland and the UK. What is found are significantly different intensities of application between the countries, with the UK applying such ideas in a much more rigorous manner than Ireland. Possible reasons for this are suggested.
\end{abstract}

\section{INTRODUCTION}

After the Second World War there was a massive expansion in the role of the state across Organisation for Economic Co-operation and Development (OECD) countries. This was driven in the main by rising expectations and the demand for 
Hyndman \& McGeough

greater equality. It was felt that in order to participate in society citizens had to have a minimum access to services such as health, education and housing (Sanderson, 1996). However, in the last thirty years major changes have taken place in relation to the role, function and management of the public sector. These changes have been termed New Public Management (NPM) (Hood, 1991). ${ }^{1}$ By the 1970s, serious doubts began to be raised about the continued expansion of the state's role. A number of reasons have been put forward to explain why the post1945 expansion of the public sector was being questioned. Among these are financial distress (Matheson and Kwon, 2003), social changes (Bovaird and Loffler, 2003), globalisation and increased competition (Flynn and Strehl, 1996), and changing perceptions of the state (Lane, 1997; Pollitt, 1993). This questioning forced governments and organisations to examine, among other things, the role of the state, the manner in which public services are delivered to citizens and the accountability of the public sector.

These drivers of change prompted the push for public sector reform. There are varying views as to what was the underlying goal, or goals, of the reform process, with some seeing it in terms of improving the performance of the public sector (Bates, 1993; Flynn and Strehl, 1996), while others saw it in terms of a fundamental questioning of the role of the state (Sanderson, 1996; Lane, 1997). It is possible to argue that both of these goals, and indeed other goals, were behind the reforms undertaken in different countries under the NPM banner. Boston (1991), Barnes and Gill (2000), and Carroll (1995) suggest a wider set of goals which, they argue, drove the reform process. These include the need to improve the overall efficiency and effectiveness of public expenditure, to reduce overall levels of expenditure, to improve the accountability of public sector organisations, to improve the transparency of the public sector, to enhance the responsiveness of public sector organisations to citizens, and to improve trust in the public sector.

The drivers of change and the goals of the reform process had a major influence on the types of changes brought into the public sector, something referred to by Hood (1995, p. 95) as the 'dimensions of change'. These included disaggregation (involving the breaking up of public sector organisations into smaller units with quite specific purposes), competition (including competition between public sector organisations and private sector operators), greater use of private sector management practices, much more concentration on resources used and results achieved, a greater emphasis on active control (where managers are actively involved in the day-to-day running of their organisations), standards of performance (where performance is measured against defined benchmarks), and a focus on output and outcome measures (with emphasis being placed on what organisations are producing, not just on what they are spending).

As can be seen, one important aspect of these changes, which is related to the key goals of NPM, is an increasing use of quantitative measures of performance as a support to better decision making and more appropriate accountability in the public sector (related to the last four of Hood's dimensions of change outlined above). Driven by the NPM agenda, many public sector organisations have sought to develop targets that cover all aspects of an organisation's performance. However, the extent to which performance measurement and performance 
management have been a focus varies considerably between countries (Hood, 1995; Olson, Guthrie and Humphrey, 1998). The key objective of this paper is to examine the possible role of quantitative targets and measures in public sector organisations in general and, through an exploratory study of annual reports, the nature and breadth of the usage of such measurements are analysed in a comparative study of the Republic of Ireland (Ireland) and the UK. In addition, the paper will explore possible reasons for the different levels of adoption of performance measurement ideas in the UK and Ireland. In terms of the format of the paper, the following approach is taken. The next section discusses what is meant by performance information and explores its potential uses in both internal planning and external reporting. The difficulties of measuring performance in the public sector are then reviewed as a basis for interpreting the later empirical research. The reasons why different countries have implemented NPM reforms at different levels of intensity will then be examined. Following this, the specific contexts of both the UK and Ireland with respect to NPM and performance measurement in the public sector are explored. The method used in this study is then outlined and the results are presented. In the final section the results are discussed.

\section{PERFORMANCE MEASUREMENT}

\section{Performance Explained}

It is common to view the performance of a public sector organisation in terms of a simple production model consisting of three stages (inputs, outputs and results). Inputs are the resources used to provide a product or service (e.g. staff, money, equipment). Outputs represent the activities carried on by the organisation, or the immediate products or services generated by the organisation (e.g. number of visits made, number of passports issued). Results (or outcomes) represent the impact of the product or service on society (e.g. a healthier population, safer roads).

In such a model, the two key criteria for judging performance are efficiency and effectiveness. While other criteria (such as economy, efficacy, electability and equity) are sometimes added, efficiency and effectiveness are the dominant terms used in discussions on performance in public sector organisations. Effectiveness is concerned with the relationship between the outputs or results of an organisation and its objectives (or targets). For example, if the target is to ensure that a certain percentage of 11-year-olds achieve a particular level in mathematics, a measure of effectiveness would compare the percentage actually achieving this level (possibly captured through the use of a particular testing instrument) with the objective. Similarly, if the target is to carry out 100 medical operations of a particular specification, a measure of effectiveness would compare the actual number carried out (presumably each passing a quality threshold) with the objective. In practice, most public sector organisations have a variety of objectives and targets, many related to aspects such as volume of service provided and quality of service provision. Efficiency is the ratio of outputs to inputs, or the amount of input per unit of output. For example, an efficiency measure could be cost (an input) per operation 
Hyndman \& McGeough

(an output), or the number of cases handled (an output) per employee (an input). Two key reasons for measuring performance are, firstly, that it provides essential information to improve management within the public sector and, secondly, that it can form the basis for discharging accountability.

\section{Performance Information and Planning and Control}

The need to plan and control the performance of public sector organisations, with a view to improving performance, has been a central issue in a number of public sector initiatives in a range of countries that have embraced NPM ideas. These initiatives have often emphasised the importance of quantification in the public sector, specifically in the context of a highly rational model of management behaviour. Significant themes connected to this rational management approach, frequently drawing extensively from the writings of Drucker (1954) and Argenti (1980), are that strategy should come about by highly systematised forms of planning and that there is a need for specific and quantified targets. It is argued that performance information is necessary to improve management within the public sector. In such a scheme, the importance of establishing clear links (or alignment) between the various levels of planning and control is stressed. In these writings it is often argued that by having targets for performance, and by measuring achievements against targets, a basis for better management within the public sector is provided. It is suggested that this will give direction to activities and provide a basis for evaluating whether the organisation has been effective and efficient.

Related ideas occur in goal setting theory, which was originally developed by Locke (1968) to explain human action in specific work situations. The two main thrusts of the theory are that specific goals lead to higher performance levels than general goals, and that difficult goals are positively and linearly related to performance. The theory asserts that if managers know specifically what they are attempting to achieve, they are motivated to exert more effort which, in turn, increases performance (Locke and Latham, 1990, 2002), although it is acknowledged that task difficulty (which is associated with difficult-to-measure goals) reduces the impact on performance (Locke and Latham, 1990).

Hyndman and Eden (2001) suggest that the thrust of many official UK government publications is that managers need to have a clear view of their objectives and to have the means of assessing performance. Similar views are incorporated into a conventional planning and control model developed by Hyndman and Anderson (1997) that involved an objectives-plan-targets-monitor-control approach. Such a focus requires organisations to set out clearly what it is they want to achieve in terms of desired performance, to develop appropriate strategies to ensure such achievement, and then to measure what they are actually achieving and compare it with planned achievements. In such a model, managers would be responsible for examining any variances in performance and would be accountable for the results achieved by the organisation.

This approach requires public sector organisations to set performance targets and examine performance in the light of the overall objectives of the organisation. 
Hyndman and Eden (2000) suggest that a completely rational system might work in the following manner:

[O]bjectives would be clearly linked to mission statement, each objective would have a number of key targets, and each key target would spawn a number of linked operational targets and targets would not be set that were not linked to objectives (Hyndman and Eden, 2000, p. 179).

Similarly, the New Zealand Pathfinder Project (a co-operative venture involving eight government departments striving to develop better outcome measures) suggested that the first step for each organisation or unit within a diversified organisation was the identification of a 'few vital' outcomes rather than a plethora of outcomes (Pathfinder Project, 2003). These, it was argued, should underpin the organisation's ability to develop a results orientation. The Pathfinder Project (2003) goes on to suggest that the key criteria of these outcomes should align with the organisational mission, be clearly linked to the organisation's outputs and inputs, measure the benefits experienced by clients, support the organisation's decision-making processes, including resource decisions, and be measured using reliable data that is obtainable at a reasonable cost.

However, the difficulty of identifying outcomes, and the potential relationship between inputs, outputs and outcomes, is highlighted in a HM Treasury public sector guide (2001), which provides a synthesis of the key concepts and ideas behind good performance information practices. Here, the problem of approximating anything like perfect outcome measures is stressed, and it is argued that:

Ultimately, we are aiming to improve outcomes, and so should measure them. But sometimes outcomes can be hard to measure. And we need to understand how inputs and outputs and associated processes are contributing to outcomes (HM Treasury, 2001, p. 3).

\section{Performance Information and Accountability}

Accountability has been defined by the Government Accounting Standards Board as:

[B]eing obliged to explain one's actions, to justify what has been done ... accountability requires governments to answer to the citizenry - to justify the raising of public resources and the purposes for which they are used (GASB, 1987, p. 21).

There may be different bases of accountability. Stewart (1984) suggests a ladder of accountability, distinguishing between, for example, 'performance accountability' and 'accountability for probity and legality'. He argues that an accountability information system should report on all levels of accountability and this will result in a system which reports both financial information and output and outcome information. 
Hyndman \& McGeough

Some have viewed the disclosure of performance information as an essential aspect of the principal-agent relationship in the public sector. For example, Hyndman and Anderson (1997) argue that the principal (often the public or the government as a proxy for the public) transfers to an agent (the public sector organisation) resources and expectations regarding the transfer. These expectations which, as Laughlin (1990) highlights, are often complex and may be written and explicit or unwritten and implicit - form the basis of the accountability relationship. In many cases these expectations are framed extensively in terms of performance and it is through the provision of performance information that accountability is discharged.

A number of writers (Gibson, 1978; Gray, 1983; Hedlund and Hamm, 1978; Hyndman, 1990) have suggested that in the not-for-profit sector generally there may be a predisposition to overemphasise the discharge of accountability for probity and legality, possibly through the provision of traditional financial accounting information, at the expense of wider performance information. However, the importance of performance information in the discharge of accountability by public sector organisations is argued forcefully by Mayston (1985), Miah (1991) and Boyne and Law (1991). In the latter case it is suggested that in the absence of such information 'the concept of accountability and indeed the whole democratic process is simply a sham' (Boyne and Law, 1991, p. 179). Hyndman and Anderson (1992), in contrasting performance accountability with financial accountability, and in highlighting the overriding importance of performance information, argue that for a not-for-profit organisation (NFPO) to discharge its accountability:

[I]t is necessary to disclose information regarding performance. While financial accountability is important, possibly to establish probity or legality in handling public funds, performance information is paramount. Therefore, without adequate means of evaluating and reporting on such issues, the discharge of accountability by NFPOs is seriously weakened (Hyndman and Anderson, 1992, p. 54).

The GASB (1987) highlights two groups who have a particular need for information from public sector organisations: the citizenry, and legislative and oversight bodies. The information needs of each of the above groups may be different. For example, the citizenry may be most interested in the results, or effectiveness, of an organisation, while the concern of oversight and legislative bodies may be jointly focused on wider performance information, including efficiency, and probity. Many of the recent NPM reforms have emphasised the need for the use of performance information in discharging accountability (see, for example, the arguments for the publication of 'league tables' for schools, hospitals and universities by the UK government). It could be suggested that while obfuscation of performance may suit some managers, the external pressure provided by the disclosure of performance information encourages a focus on performance and provides a catalyst for managers as they seek to achieve performance improvement.

It has been argued that the development of performance information by public sector organisations and its use in reporting is necessary to justify funding and to counter possible criticisms of poor management and ineffectiveness. 
Performance information gives a visibility to the resources, activities and achievements of a public sector organisation, thus enabling informed discussions and decisions. In addition, the need to discharge performance accountability encourages management to concentrate on the issues that are frequently of importance to those stakeholders who are outside the immediate management of the organisation and often provide the resources for the organisation to function (in the case of public sector organisations these stakeholders often comprise the public or their elected representatives). Edwards and Hulme assert that the absence of accountability, and in particular performance accountability, 'begins to make the likelihood of ineffective or illegitimate actions by an organisation much more probable' (1995, p. 9). With respect to public sector organisations, where accountability is weak, management might have limited incentive to manage the organisation's funds efficiently and effectively.

The New Zealand-based State Services Commission (1999) suggests that over time the emphasis in performance reporting has changed from the reporting of inputs to the reporting of results. Such a change encourages managers to spend less time accounting for where money (the inputs) is spent and more time accounting for the outputs and outcomes achieved. Fuller and Roffey (1993) argue that this change in emphasis needs to be underpinned by clear objectives and standards of service against which organisational performance can be measured (requiring detailed specification of the outputs expected in advance), performance measures to assess results (with an emphasis on usefulness as opposed to precision), robust information systems to support organisational decision making, and timely and understandable reporting of results.

\section{Difficulties of Measuring Performance in the Public Sector}

The use of a planning and reporting system utilising specific and quantified goals, objectives, targets and performance measures is not without problems. It must be recognised that while many pronouncements by governments that have embraced NPM have been couched in terms of efficiency and effectiveness, with their emphasis on rational management and clear means-ends relationships, the application of such ideas in complex organisations is problematical. For example, McSweeney (1988), in discussing value-for-money audits, examines a number of the difficulties of such an approach. These include the lack of a direct and knowable link between intentions and outcomes, the difficulty of identifying explicit and quantifiable goals, the ability to manipulate information, a concentration on quantification, and a lack of regard for qualitative factors. These issues largely reflect the inherent difficulties of measuring performance in any NFPO (for further discussion of such difficulties see Connolly and Hyndman, 2003). A detailed discussion of these difficulties and more specific criticisms is beyond the scope of this paper; however, some examples may help in interpreting the later empirical work reported in this paper.

If systems are implemented and operated in very rigid ways, major dysfunctional effects may occur. This may be the case where a 'one size fits all' view is 
Hyndman \& McGeough

taken. Smith (1993) has suggested a number of possible adverse consequences, including tunnel vision, suboptimisation, myopia, ossification and misrepresentation. Hofstede argues that consideration must be given to the organisational context in which a system operates, and highlights the danger that 'the more formalised a control system, the greater the risk of obtaining pseudo-control rather than control' (1981, p. 211). He goes on to suggest that where outputs are ambiguous and are not easily measured, and where the effects of management intervention are not well known, the adoption of mechanistic, rationalistic, techniques-driven management systems are likely to have unintended consequences.

Some have questioned the use of a rational management approach in the public sector because of the way in which changes have been implemented. In certain cases this can lead to inappropriate behaviour on the part of managers or misjudgements by outside parties. Hopwood (1985), in presenting field evidence from one public sector organisation, suggested that changes that were articulated in terms of improving management were, in reality, more to do with external accountability and establishing legitimacy. Other criticisms of the rational management approach relate to the perceived lack of understanding of the political and social contexts into which these systems are introduced. For example, Broadbent and Guthrie (1992) argue that the changes that are being implemented in the public sector are often unevaluated, neglect the social side of organisations, deflect focus from key issues and may be detrimental to the best interests of society.

There is also a possible danger that defining a mission and objectives, and setting targets and reporting performance against them, will degenerate into a formal ceremony that has little impact on the behaviour of managers and does nothing to improve the efficiency, effectiveness and accountability of organisations. Thompson (1995) warned that unless care was taken in developing useful systems, there was a possibility of the whole exercise lapsing into a senseless ritual, which, sooner or later, would be abandoned as cost-ineffective. This view is expressed even more strongly by Sharifi and Bovaird:

[I]t might ... be argued that in the public sector the potent symbol of performance orientation has helped to establish the myth that public sector organisations have a sense of direction and an explicable rationale for their actions. This myth is reinforced by the rituals of performance measurement and reporting (1995, p. 477, emphasis in original text).

\section{Intensity of Adoption of NPM Reforms}

International comparisons of NPM-style reforms across a number of countries indicate that these reforms are being implemented at a quicker pace and more enthusiastically in some countries compared to others (Hood, 1995; Flynn and Strehl, 1996; Pollitt and Bouckaert, 2004). For example, Hood (1995), in countering the suggestion that NPM is more obviously associated with right-wing governments, produced an analysis (see Table 1) outlining the degree of NPM intensity in various countries and the political orientation of the national 
NPM and Performance Measurement

TABLE I: NPM INTENSITY AND POLITICAL ORIENTATION

\begin{tabular}{llll}
\hline & \multicolumn{3}{c}{ Political Orientation } \\
\cline { 2 - 4 } NPM Intensity* & Left & Centre & Right \\
\hline High & Sweden & Australia & UK \\
& & Canada & \\
Medium & New Zealand & \\
& France & Austria & \\
& & Denmark & \\
& & Finland & \\
& & Italy & \\
& & Netherlands & \\
& & Portugal & JSA \\
Low & & Germany & Japan \\
& & Switzerland & Turkey \\
\hline
\end{tabular}

Source: adapted from Hood (1995), p. 100

*It should be noted that while Ireland is not included in the above table of Hood's analysis of NPM intensity and political orientation, elsewhere in Hood's paper it is identified as a country having medium NPM intensity (Hood, 1995, p. 104, Table 4).

government in each of these countries at that time. Basically he argued that political orientation (of left, centre or right) could not explain the degree of implementation of NPM ideas. ${ }^{2}$

Hood (1995) went on to suggest that the adoption of NPM approaches requires motive and opportunity. Motive arising from the savings that will occur once NPM approaches are implemented. Opportunity occurring when there are limited constitutional checks on central government.

With respect to opportunity, Flynn and Strehl (1996) provide some support for Hood's view, when they argue:

Constitutional arrangements and the legal basis of the state are clearly an important influence both on the nature of managerial work and the extent and direction of reforms ... In a federal structure, the influence of central government may be small (Flynn and Strehl, 1996, p. 6).

Similarly, Pollitt and Bouckaert (2004) suggest that reforms are easier to push through in a centralised state than in a decentralised state, and in a state that operates a majoritarian approach to government rather than a consensual approach. In particular they argue that all reforms produce 'winners' and 'losers' and that in a consensus-driven system these 'losers' are likely to be represented in the government. On the basis of this contention, they produced a three-by-three matrix (see Table 2) that explored centralisation/decentralisation and majoritarian/consensus, and located countries within this matrix. In their analysis, they suggest that the speed and severity of public sector reforms decline as you move from left to 
Hyndman \& McGeough

TABLE 2: STATE STRUCTURES AND THE NATURE OF EXECUTIVE GOVERNMENT

\begin{tabular}{llll}
\hline & Majoritarian & Intermediate & Consensual \\
\hline $\begin{array}{l}\text { Centralised } \\
\text { (Unitary) }\end{array}$ & New Zealand & France & Italy \\
$\downarrow$ & UK & & Netherlands \\
$\begin{array}{l}\text { Intermediate } \\
\downarrow\end{array}$ & Sweden & & Finland \\
$\begin{array}{l}\text { Decentralised } \\
\text { (Federal) }\end{array}$ & Australia & & \\
& Canada & Belgium & \\
\hline
\end{tabular}

Source: adapted from Pollitt and Bouckaert (2004), p. 47

right and that the scope of reform (the amount of the public sector impacted by any one reform programme) declines as one moves from top to bottom.

When considering Tables 1 and 2 together, it can be seen that of the five countries in Table 1 with high NPM emphasis, two (the UK and New Zealand) are majoritarian, centralised states, two (Canada and Australia) are majoritarian, decentralised states and one (Sweden) is a majoritarian, intermediate state. But as you move from left to right in Table 2 (to the states that operate intermediate and consensual approaches to politics), all the countries listed fall into the medium or low intensities of NPM usage using Hood's (1995) framework (France, Belgium, Germany, Italy, Netherlands and Finland).

Another factor possibly affecting the extent to which NPM ideas are embraced is the diversity of policy advice on reform issues to ministers. Pollitt and Bouckaert (2004) argue that the wider the range of advice, the greater the chance that new ideas will influence ministers. They suggest that, for example, in the UK when Margaret Thatcher was Prime Minister she sought advice from right-wing think tanks because of her suspicions of civil servants. This possibly increased exposure to NPM ideas to a much greater extent than would have been the case if civil servants had filtered ideas.

With respect to culture, Pollitt and Bouckaert (2004) further argue that the cultural climate of a country has a major influence on the success or otherwise of a public sector management reform programme. Hofstede (2001) identifies five critical cultural elements: power distance, uncertainty avoidance, masculinity versus femininity, long term versus short term, and individualist versus collectivist orientation. Individual countries, including Ireland and the UK, were scored using an index based on these cultural elements. The scores for Ireland and the UK were similar on the first four elements; however, on the last element (individualism versus collectivism), the UK was shown to have a much more individualistic orientation than Ireland. This might possibly indicate a more accepting context for the introduction of NPM ideas in the UK. At the same time a more collectivist orientation may militate against the introduction of NPM reforms in the Irish public sector. 


\section{THE DEVELOPMENT OF PUBLIC SECTOR PERFORMANCE MEASUREMENTS IN THE UK AND IRELAND}

The UK and Ireland have been actively involved in the development of performance information frameworks for their public sectors, although to varying degrees and over differing timescales. It is clear that the UK was an early adopter of the NPM 'forms of change' outlined previously and tended to take major steps in the reform process (for example, the Next Steps Initiative of the late 1980s and the marketisation of the NHS in the 1990s were clear examples of this). In contrast, Ireland was a relatively late adopter and has seemed to favour a more gradual process. However, Hood (1995) placed Ireland along with Denmark and the Netherlands in the medium category with regard to NPM emphasis. Nonetheless, the UK and Irish contexts have been relatively comparable. Traditionally, because of historical factors, the UK and Irish public administration systems have been somewhat similar. In economic terms the two countries, which are major trading partners, often experience parallel economic cycles. The UK experienced economic difficulties in the 1970s and 1980s. Moreover, the UK elected the right-wing Conservative party, led by Prime Minister Thatcher, to power in 1979. What followed was a period of early and intense introduction of NPM reforms. However despite very severe economic difficulties in Ireland, particularly in the 1980s, evidence of any significant impact of NPM reforms is not available until well into the 1990s. While Ireland, like the UK, is a centralised state, there are crucial differences. Firstly, Irish politics is largely non-ideological. Secondly, in Irish politics, largely because of the proportional representation voting arrangements in national elections, often the government consists of a coalition of parties rather than a majoritarian government, as is the norm in the UK. Perhaps as a result of the above there is a more consensual approach to policy making in Ireland, evidenced most strikingly in a series on national pay agreements involving a range of the social partners (mainly government, employers and unions).

\section{The Evolution of Performance Measurement in the Public Sector in Ireland}

In the late 1980s and early 1990s there was strong interest and awareness in Ireland of the NPM reforms being introduced in many OECD countries, perhaps particularly in New Zealand and the UK. One important aspect of interest was the NPM focus on performance measurement as a basis for performance management. A major initiative under the NPM banner in Ireland was the launch in 1994 of the Strategic Management Initiative (SMI) by the then Taoiseach (Prime Minister), Albert Reynolds. The overall objective of the SMI (to improve the delivery of public services) was clearly related to performance improvement, and it was argued that, as a result of the SMI, public organisations would contribute more to economic and social development, and public resources would be used effectively by these organisations.

The SMI was developed further in 1996 when the Taoiseach launched the Delivering Better Government (DBG) report (Department of the Taoiseach, 1996). 
Hyndman \& McGeough

Again, the issues of performance measurement and performance management were to the fore. The report envisaged that the key priorities of the government would be set out in Strategic Results Areas (SRAs) and that individual departmental statements of strategy, setting out the contribution that departments will make to the achievement of the SRAs, would flow from these. Furthermore, it was anticipated that the high-level departmental objectives would cascade down into the daily activities of the department, thus allowing key ideas from the SMI to embed themselves in the regular work of the department. The report also argued that there must be:

[A] recognition that performance management is a process, based on the active and continuous management of work relative to a pragmatic, relevant set of performance measures or indicators, and not a routine filling of forms (Department of the Taoiseach, 1996, p. 31).

In DBG it was recognised that an important element of this process will be the monitoring of progress in achieving goals. It was argued that if performance management is to be integrated into the day-to-day operations of a department, appropriate performance indicators (PIs) must be developed, and these must link the work of individuals or divisions to the departmental objectives. The recommendations of DBG were implemented in the Public Service Management Act (Government of Ireland, 1997), with specific legislative backing being given to the preparation and publication of strategy statements (with the preparation of such statements and the publication of an annual progress report being the responsibility of the secretary general of a department or the head of a scheduled office). The Act outlines what is meant by a strategy statement, and in the process highlights the critical performance-related aspects, by stating that strategy statements should:

[C]omprise the key objectives, outputs and related strategies (including use of resources) of the Department of State or Scheduled Office concerned (Section 5 (1) (a)).

In a related vein, and building on the ideas introduced in DBG, the Department of the Taoiseach (2004) suggests that objectives should be set in terms of the results required or outcomes intended, and that strategy statements should include PIs. Echoing ideas reminiscent of the rational management model, this point is developed by exhorting organisations to develop strategy statements that contain an organisation mission statement, an environmental analysis, the goals, objectives, strategies and outputs of the organisation, and PIs that can be linked to organisation objectives and are capable of demonstrating achievement. In building on this last point, guidelines contained in this document emphasise the importance of PIs as a means of monitoring progress by posing the following questions in relation to PIs:

Are performance indicators clearly associated with objectives and strategies and capable of being assessed? Do indicators cover outcome and quality as well as outputs? ... Are arrangements in place to clearly link the statement to the business 
planning and performance management and development process? (Department of the Taoiseach, 2004, p. 17).

Further guidance from the Department of Finance (2004a) suggests that the aim of business planning is to translate the goals or objectives in the strategy statement into goals or objectives for divisions, units and individuals. Again, it emphasises the centrality of matching objectives with high-level goals in an organisation, identifying the outputs (programmes, services) required to achieve these objectives, identifying daily activities and resources needed to support these outputs, and setting out useful and relevant PIs for each activity, which should allow for ongoing evaluation.

With respect to annual reports, the Public Service Management Act (Government of Ireland, 1997) requires departments to publish an annual report, with the Department of the Taoiseach guidelines (2004) on the preparation of strategy statements indicating that it should be clear from the annual report whether or not strategies set out in the strategy statement are being achieved. With such a requirement, PIs can provide a significant means of demonstrating the role that outputs are making to the organisation's objectives (related directly to the discharge of performance accountability). Given the potential importance of PIs, the Department of Finance has devoted a lot of effort to developing guidelines for their implementation (viewed as a key part of a Management Information Framework (MIF) project). The Department of Finance published three documents on PIs (2004a, 2004b, 2006a) which built on many of the issues outlined previously. These documents emphasised that the starting point for developing PIs is the outcomes set out in the strategy statement, and that these must cascade down into PIs. Furthermore, the need for clear alignment between the activities and outputs of the organisation and the desired outcomes was stressed.

There has also been a range of more recent official Irish government publications articulating the need for performance measures for both planning and control, and accountability purposes that reinforce the above themes. For example, the Department of Finance's budget document (2006b) states that in the budgeting process ministers will produce annual output statements to accompany their estimates (requests for resources) and, from 2008, these output statements will include information on outturns against targets. Furthermore, the purpose of the Expenditure Review Initiative (ERI) requires that:

Each Department should be able to 'walk' from high-level goals and output information in their strategy statements to their divisional level objectives and also be able to link these to their estimates (Expenditure Review Central Steering Committee, 2005, p. 7).

Moreover, the first formal report of the Expenditure Review Central Steering Committee notes that departments (or offices) should intensify their efforts to develop PIs designed to map progress in adding value and, with respect to annual reports, recommends that they be modified, 'to include an Annual Statement providing the link between high-level planning and goals and programme delivery, 
Hyndman \& McGeough

the use of resources and achievements' (Expenditure Review Central Steering Committee, 2005, p. 2).

\section{The Evolution of Performance Measurement in the Public Sector in the UK}

Much has changed in the UK public sector, particularly since 1979 (the advent of the Thatcher era). Large-scale privatisation, widespread market testing, the breakup of large units of government into smaller quasi-autonomous units and the increasing use of traditional private sector corporate practices are testimony to the NPM changes that have taken place. This can be seen in the 'Rayner scrutinies' of the early 1980s, the Financial Management Initiative (FMI) of 1982, the establishment of executive agencies following the Next Steps Initiative (NSI) of 1988, the Citizen's Charter of 1991 and a host of other changes in such areas as local government, health and education. One theme central to them all is that performance should be improved and such improvement must be measured in terms other than how much money is spent. Broadbent and Laughlin suggest that the launch of the FMI can be seen as a 'watershed point' (2006, p. 30) in the development of NPM in the UK, with departments required to set out their objectives and measure their performance in relation to these objectives (as well as managers having greater responsibility for delivering value for money).

With respect to the FMI, Zifcak (1994) claims that it was initially much less successful than anticipated, and argues that Australia's Financial Management Improvement Programme was more successful than the UK's FMI because the former was less top-down and more consensual than the latter. This perceived lack of success of the FMI prompted the development of the NSI, which resulted in the establishment of executive agencies, with each agency (headed by a chief executive) having responsibility for carrying out specified functions assigned to them by a supervising department. Broadbent and Laughlin (2006) suggest that such an arrangement led to central departments having a strong role to play in the setting of targets and the monitoring of agency performance in return for allowing greater freedom to individual agencies as to how money was spent.

The importance of performance information in underpinning such changes was emphasised by the UK's Comptroller and Auditor General in his evidence to the Public Administration Select Committee (PASC), where he stated:

Over the last 20 years performance measurement has developed into an important means of improving performance and reinforcing accountability ... Performance measurement has become an integral part of modern government ... Good performance information is a crucial element in helping public sector organisations to develop policy; manage their resources cost effectively; improve delivery; and account for their performance to Parliament and the general public (PASC, 2003: Minutes of Evidence, PST 54, paras. 3 and 4).

The performance focus of the UK public sector has intensified further with the introduction of Public Service Agreements (PSAs). ${ }^{3}$ This change is described 
by Broadbent and Laughlin as a 'step-change' (2006, p. 34) in the emphasis on performance information. PSAs are intended to move the focus away from inputs and processes towards delivery and results, i.e. an increased emphasis on outputs and outcomes. PSAs bring together in one document the aims and objectives of the organisation, outcome-focused performance targets and a statement as to who is responsible for the delivery of these targets. It is intended that the PSAs set out national priorities and that local organisations have freedom as to how best to achieve these outcomes in their local areas.

As well as extolling the necessity for measuring performance, official government guidance relating to performance measurement has supported such change. For example, in the early 1990s a HM Treasury (1992) document relating to executive agencies was published (although it was noted that it was applicable to all parts of the public sector). Among the key advice given in the guide was the following: no agency ought to be set more than a handful of key targets; targets will usually fall under one or other of the following broad headings - financial performance, volume of output, quality of service and efficiency; it is important that an explicit balance should be decided between the targets set for quality of service, and those covering volume of output and efficiency; targets should normally be proposed and set as part of a corporate planning process; progress against the key targets should be monitored during the year; and achievements against key targets should be included in the annual report and accounts of the agency. The guidance was peppered with examples of actual measures being used.

Another more recent public sector guide published in the UK, Choosing the Right Fabric: A Framework for Performance Information (HM Treasury, 2001), provided the public sector with a synthesis of the key concepts and ideas behind good performance information practices. The 35-page long document considered the type of information that is worth collecting as performance information, and the principles behind pulling together a set of performance measures. The role of performance information and the practical issues in putting a performance information system in place were discussed, and pointers to further sources of information and guidance were provided. The significance of performance information in strategy, policy development, business planning, performance management and accountability was discussed, and the importance of ensuring that high-level business plans are 'cascaded' through the organisation by the use of targets and performance measures was illustrated (with numerous examples provided).

\section{ANALYSIS OF ANNUAL REPORTS}

\section{Method}

The research sought to identify the nature and breadth of the quantitative performance targets and measures in public sector organisations in Ireland and the UK. A matched sample of ten UK executive agencies and ten comparable Irish public sector organisations was selected (see Appendix 1). Executive agencies were chosen because their activities have an operational concentration (and therefore are 
Hyndman \& McGeough

more likely to lend themselves to measurement and reporting), and it was expected that their Irish equivalents (being responsible for comparable activities to their matched UK counterparts) would have a similar focus. With respect to the Irish organisations, six were stand-alone state agencies while four of them were divisions or sections of central government departments.

Document analysis was used to gather data. Annual reports were accessed from the organisations' websites; with the latest available reports being used. The reports were examined to see the extent and type of performance information included in the annual reports. Annual reports are generally recognised as key documents in the discharge of accountability to external users, and public sector organisations in both Ireland and the UK are required to publish such documents. The Corporate Report states that such information packages are 'the primary means by which management of an entity is able to fulfil its reporting responsibility' (Accounting Standards Committee, 1975, p. 16). Dobell and Zussman, writing over 25 years ago, inferred that reporting systems by public sector organisations had significant deficiencies and suggested that 'more substantial annual departmental accounts should help the accountability process' (1981, p. 423). Similar sentiments are included in more contemporary Irish and UK official government publications relating to public sector service delivery (Department of the Taoiseach, 2004; HM Treasury, 2001).

For analysis purposes, information was considered disclosed if it was highlighted in some way (hard copy) and not contained in the main narrative of the annual report (soft copy). This approach was used by Hyndman and Anderson (1997) in their review of performance reporting by executive agencies, where it was argued that soft copy was difficult for users to isolate and use. While it could be argued that this is just a matter of presentation, information that is highlighted and concise was deemed to be significantly more useful in terms of communicating to users; this is particularly the case where users of annual reports have limited, or no, powers of interrogation.

To reduce subjectivity, a number of steps were taken. A set of definitions was developed to ensure that terms were being used in the same way for each organisation. In addition, a set of rules of classification was written to deal with common difficulties of analysis. For instance, only targets or measures with a numerical element (or a target completion date of a particular task) were included. For example, the Irish Marine Safety and Environment section of the then Department of Communications, Marine and Natural Resources had a target of responding to all 999 calls immediately. This was included as a target (of 100 per cent immediate response) and a measure because an actual achievement level was reported and could be benchmarked against the target. In addition, targets or measures were counted separately if several distinct and discrete aspects were included within a particular statement relating to targets or measures of performance. The UK Maritime and Coastguard Agency provides an example of this. The following target-related statement: 'provide initial responses on grant applications within 15 working days and final response within 6 weeks of receipt of final application' was made and actual measurement of performance was provided against each aspect (initial response and final response). This was counted as two 
targets and two actual measures. Again, to improve objectivity, the analysis was undertaken by two individuals, before discussing and agreeing the results. No judgment was made on the appropriateness of the targets set and actual performance level achieved.

\section{Results}

Initially, the length of the annual reports was reviewed (see Appendix 2). As is seen, the average length of the UK reports was 84 pages, compared to 34 for the Irish reports (where the unit was part of a department, only the pages covering that unit were counted). To an extent, it may be argued that some of this difference may be accounted for by the fact that some of the Irish organisations were sub-sections of departments. Given that all the UK organisations were standalone agencies, Appendix 2 also shows a split between the stand-alone agencies in Ireland and their UK equivalents (six organisations) and those Irish organisations that were subsections of a larger department (four organisations). As can be seen, the annual reports of the stand-alone Irish agencies have an average length of 54 pages, compared to 78 pages for their UK equivalents. A comparison of the length of annual reports shows a stark contrast between the 4 Irish units that are reported as part of their parent department and their UK equivalents (6 pages for the Irish units as against an average of 94 pages for UK agencies). Thus, the fact that a unit is part of a larger department (which reports in total on what has happened at departmental level) may lead to less detail being provided in the annual report at unit level. This lack of separation from their department may make it problematic for a section to become what Miller and O'Leary (1987) call a 'governable unit', suggesting that smaller units make it easier for activities (and indeed individuals) to be isolated and evaluated in greater detail. The main findings from the empirical research are examined with respect to the extent of performance targets/measures reported, and the types of performance targets/measures being used.

\section{The Existence of Performance Targets and Measures}

The annual reports were analysed to identify the number of targets and measures in each document. Table 3 details the findings with respect to this, highlighting numbers by individual organisation (distinguishing between the UK organisation and its Irish comparator) and the average of all organisations within each jurisdiction. In addition, it distinguishes between the stand-alone agencies in Ireland and their UK equivalents (six organisations) and those Irish organisations that were subsections of larger departments (four organisations) together with their UK equivalents. As can be clearly seen, the disclosure of performance targets and measures in annual reports is much higher in UK executive agencies than in their Irish counterparts. In relation to performance targets, the UK organisations average 12.5 (ranging from a high of 26 to a low of 6), compared to 5.2 for Ireland 
Hyndman \& McGeough

TABLE 3: NUMBER OF PERFORMANCE TARGETS AND MEASURES INCLUDED IN ANNUAL REPORTS

\begin{tabular}{|c|c|c|c|c|}
\hline & \multicolumn{2}{|c|}{ UK } & \multicolumn{2}{|c|}{ Ireland } \\
\hline & Targets & Measures & Targets & Measures \\
\hline \multicolumn{5}{|l|}{ Stand-Alone Agencies (UK/Ireland) } \\
\hline Land Registry/Land Registry & 10 & 31 & 0 & 8 \\
\hline Ordnance Survey/Ordnance Survey & 6 & 13 & 0 & 0 \\
\hline $\begin{array}{l}\text { Companies House/Companies } \\
\text { Registration Office }\end{array}$ & 12 & 18 & 33 & 33 \\
\hline Courts Service/Courts Service & 13 & 12 & 0 & 3 \\
\hline $\begin{array}{l}\text { Insolvency Service/Office of the } \\
\text { Director of Corporate Enforcemen }\end{array}$ & 26 & $4 I$ & 0 & 8 \\
\hline $\begin{array}{l}\text { Employment Tribunals Service/ } \\
\text { Employment Appeals Tribunal }\end{array}$ & 10 & 13 & 0 & 7 \\
\hline \multicolumn{5}{|l|}{$\begin{array}{l}\text { UK Stand-Alone Agencies/Irish } \\
\text { Subsections of Department }\end{array}$} \\
\hline $\begin{array}{l}\text { UK Passport Service/Department } \\
\text { of Foreign Affairs* }\end{array}$ & 14 & 14 & 0 & 0 \\
\hline $\begin{array}{l}\text { Maritime and Coastguard Agency/ } \\
\text { Maritime Safety and Environment*** }\end{array}$ & 8 & 16 & 12 & 13 \\
\hline $\begin{array}{l}\text { Maritime Fisheries Agency/ } \\
\text { Marine Resource Management** }\end{array}$ & 14 & 15 & 7 & 14 \\
\hline $\begin{array}{l}\text { Patent Office/Department of } \\
\text { Enterprise, Trade \& Employment** }\end{array}$ & 12 & 12 & 0 & 0 \\
\hline Total Targets/Measures & 125 & 185 & 52 & 86 \\
\hline Average of All Organisations & 12.5 & 18.5 & 5.2 & 8.6 \\
\hline $\begin{array}{l}\text { Average of Six Matched UK Stand- } \\
\text { Alone Agencies/Irish Agencies }\end{array}$ & 12.8 & 21.3 & 5.5 & 9.8 \\
\hline $\begin{array}{l}\text { Average of Four Matched UK Stand- } \\
\text { Alone Agencies/Irish Subsections } \\
\text { of Departments }\end{array}$ & 12 & 14.3 & 4.8 & 6.8 \\
\hline
\end{tabular}

(ranging from 0 to 33). With respect to measures, the pattern was similar (UK average 18.5, range 12 to 41 ; Ireland - average 8.6, range 0 to 33). To a large extent the average in Ireland, in the case of both targets and measures, was extensively affected by the fact that the Companies Registration Office was somewhat of an outlier (having 33 targets and measures, while 7 Irish organisations had no targets and 3 Irish organisations had no measures of performance). This contrasts with the UK organisations, with every executive agency having at least several targets (minimum 6) and a fair number of measures (minimum 12).

Differences between Irish stand-alone agencies and Irish units that were subsections of a larger department were marginal (average for Irish stand-alone 
agencies - targets 5.5, measures 9.8; average for subsections of departments - targets 4.8, measures 6.8) Given that the average for the four comparator UK stand-alone agencies that were matched with their Irish subsections of departments was lower than the overall average for all UK organisations, too much should not be inferred from these differences. In addition, the fact that one of the stand-alone Irish agencies (the Companies Registration Office) had by far the most targets and measures of any Irish organisation (33 targets and 33 measures) makes generalisations from averages difficult. Indeed, only one of the six Irish stand-alone agencies (again the Companies Registration Office) had any targets (compared with two of the four subsections of departments).

The targets in both Ireland and the UK were widely used as benchmarks against which to judge actual performance. In Ireland all of the targets included in the annual reports had associated measures (although this is not highlighted in Table 3); in other words, when a target was published in the annual report the actual performance against that target was also disclosed. In total, 52 of the 86 Irish measures related to the 52 targets set by Irish organisations (with the other measures largely complementary to the main thrust of the targets). Similarly, in the UK the vast majority of the targets had a corresponding measure (121 out of 125). The only exceptions to this were the Courts Service and the UK Insolvency Service. In the case of the Courts Service one target was not measured and an explanation was given that the means of measuring progress had not yet been put in place (suggesting that in future a target would be set when this dimension of the measuring process had been established). In the case of the Insolvency Service it was explained that three targets relating to reductions in fees could not be implemented because of delays in agreeing budget allocations. In the context of accountability, this matching of targets and measures enables the reader of the annual report to evaluate the work of the organisation and make a judgment on the performance of the organisation.

While measures of performance were made against all targets in the annual reports of the Irish organisations, it should be noted that these targets related to only three organisations (Maritime Safety and Environment and Marine Resource Management - which are both part of the Department of Communications, Marine and Natural Resources - and the Companies Registration Office). The other seven Irish organisations highlighted no targets, although four of them had performance measures. As outlined above, targets and measures were only counted if they were highlighted in some way; thus, if the targets and measures were included in a table, or set apart by bold print or boxed off, they were counted. However, if they were embedded in the main text (and not set apart in any way), they were not counted. It should be noted that several of the organisations (particularly the Irish organisations) reported on activity levels in their annual reports (although did not refer to targets) but did not highlight these. However, by contrast, all of the UK organisations had at least several highlighted targets and measures, the vast majority of the organisations having specific, set-apart sections in their annual reports identifying and highlighting performance against target.

This absence of performance targets in the Irish organisations may arise from an inability or unwillingness to develop performance targets from high-level 
Hyndman \& McGeough

goals. For example, in the Irish Consular and Passport section of the Department of Foreign Affairs annual report a high-level goal is stated as being to 'provide a modern and efficient passport and consular service' but, as seen in Table 3, there is no disclosure of any performance targets relating to this or anything else. This is possibly indicative of no attempt being made in the organisation to break this high-level goal into a series of performance targets. Such lack of focus, evidenced by a dearth of specific and measurable targets, makes performance measurement and performance improvement difficult (if one accepts the main thrust of goal setting theory discussed earlier), and certainly runs counter to the rational management ideas contained in so much official Irish government literature and guidance on performance measurement. This contrasts with the UK Passport Service (UKPS), which has identified 'responding to customer needs' as one of the key areas to manage. Under this heading the UKPS identifies the goal 'to ensure that customers are satisfied with the standards of our service' and then breaks this down into the following performance targets: to ensure a customer satisfaction rating of 95 per cent (with an actual measurement being achieved by means of a survey); and to ensure that 92 per cent of customers are seen within 20 minutes of their appointment time. The UKPS then reports actual performance against these targets.

Another example of the lack of performance focus in Ireland is seen with respect to Ordnance Survey Ireland (OSI), which states its mission to be 'excellence in providing quality mapping and spatial information services to meet society's needs'. OSI goes on to identify a number of strategic themes, focusing on two areas in particular: 'to be an efficient organisation offering excellent value' and 'to develop our people and culture to underpin the success of the business'. Although these themes are further broken down into a number of activities that should be undertaken, no performance targets relating to them are developed (making it impossible to identify success or otherwise). However, while UK Ordnance Survey sets out its strategic objectives in detail in a similar fashion (for example, it states that it seeks to 'develop a business that focuses clearly on the needs of customers and continuously improves customer satisfaction'), a reasonably extensive range of performance targets is developed and used as a basis for judging performance. For example, a target 'to continuously improve the timeliness of the supply of our data to customers by processing and dispatching at least $95 \%$ of orders within agreed timescales' is disclosed and performance is then measured and reported against the target.

The three Irish public sector organisations where particular progress appears to have been made on the development of performance targets and measures were Maritime Safety and Environment, and Marine Resource Management (both subsections of the Department of Communications, Marine and Natural Resources) and the Companies Registration Office. With respect to Maritime Safety and Environment, the Department set out its core policy goal as being 'to establish, promote and enforce safety and security standards, and, by doing so, prevent, as far as possible, the loss of life at sea and on inland waters and other areas, and to provide effective emergency response services'. This was then broken down into four strategic objectives, one of them being 'to develop and 
implement international and domestic safety standards'. Under this objective a number of activities were identified and from these activities targets were developed and, subsequently, performance was measured. For example, with respect to the activity of licensing of passenger boats, the annual report sets out the standard of service (target) as being 'all boats to be surveyed within four weeks of receipt of application for a licence and, depending on the outcome of the survey, licence to be granted' and the actual performance against this target was disclosed. A similar pattern is seen with respect to the UK Maritime and Coastguard Agency. For example, one of the stated goals is 'a reduced rate of accidents and accident-related deaths involving UK registered merchant ships and fishing vessels.' The UK agency then states a target for carrying out planned ship inspections of 97 per cent of ships in the period to be inspected, and then highlights actual performance against this.

The research shows that, generally, the UK organisations have more established performance measurement systems than their Irish equivalents. The nature of the research, focusing on the annual reporting mechanism, demonstrates greater concentration on performance accountability by UK agencies and suggests greater use of objectives and targets in the planning and control systems (with the absence of targets in the Irish annual reports possibly being indicative of a lack of availability of such information in the planning process). The contrasting patterns in the development of performance information would seem to have little to do with the nature of the work (the organisations studied being matched by area of activity in each jurisdiction). Furthermore, while it might have been expected that Irish stand-alone organisations would have more comprehensive systems of performance targets and measures than Irish organisations that were parts of larger departments (the 'governable unit' expectation), there was no evidence of this in the research.

\section{Types of Performance Targets Used}

As well as considering the number of performance targets and performance measures that are produced by public sector organisations, this research also considered the nature and breadth of targets and measures used in reporting. The performance of a private sector company is ultimately judged on profit; no similar measure exists for public sector organisations. Public sector performance is multi-faceted and therefore requires a range of measures (Jackson, 1988). HM Treasury (1992) outlines a taxonomy covering four broad areas (financial performance, volume of output, quality of service and efficiency - including cost per unit of output) and recommends that an explicit balance needs to be developed between these. Apparently embracing key ideas from goal setting theory and the rational management literature, key themes of this guidance are that targets set should align with an organisation's overall strategy and be balanced in terms of its main thrusts.

Table 4 explores this, and considers the number of targets and measures included in the annual reports, analysed by jurisdiction and by target/measure 
Hyndman \& McGeough

TABLE 4: TYPES OF PERFORMANCE TARGETS AND MEASURES DISCLOSED IN ANNUAL REPORTS

\begin{tabular}{llllll}
\hline & \multicolumn{2}{c}{ Targets } & & \multicolumn{2}{c}{ Measures } \\
\cline { 2 - 3 } Type of Target/Measure & UK & Ireland & & UK & Ireland \\
\hline Financial performance & 4 & 0 & 9 & 1 \\
Volume of output & 9 & 0 & & 35 & 27 \\
Quality of service & 81 & 43 & & 107 & 46 \\
Efficiency (inc. unit cost) & 13 & 0 & 10 & 0 \\
Other & 18 & 9 & 24 & 12 \\
Total & 125 & 52 & 185 & 86 \\
\hline
\end{tabular}

type. The analysis largely uses the HM Treasury (1992) framework, distinguishing between financial targets, volume of output targets, quality targets and efficiency targets. In addition, a number of targets or measures could not easily be attributed to any one of these four categories and these were counted as 'other' targets. Examples of financial targets/measures might include degree of cost recovery through charges, surplus on commercial activities or having lived within the financial budget. In the case of volume of output targets/measures, the particular area measured would tend to be very specific to the nature of the work of the organisation. For example, the number of course days provided or the number of student days taught might be used by a training organisation (combined, hopefully, with quality indicators), whereas the number of job placings might be key to an organisation concerned with facilitating employment. The choice is especially wide when the nature of the output varies (e.g. with research organisations), with a possible distinction between 'intermediate outputs' (a step towards producing something) and 'final outputs' (the ultimate outcome). For example, it could be argued that the final output of a vehicle testing organisation may be such things as the impact on road safety or environmental pollution, but for the purposes of determining targets and developing measures it may be preferable to concentrate on the direct outputs (possibly because the final output may occur much later than the intermediate output and is often affected by various factors unrelated to the action of the agency). With respect to quality targets/measures these may be categorised into those relating to the quality of the product (e.g. accuracy) and those relating to aspects of the process of delivery (such as timeliness, turnaround time and customer-supplier relationship). In relation to efficiency targets and measures, as well as the importance of unit cost figures that could be used by most public sector organisations (which link the costs, an accumulation of inputs valued using a common financial benchmark, to the units of output), targets/measures such as the number of tests or operations conducted (an output) per employee (an input) or capacity utilisation (in terms of, for example, accommodation available or places available) could be useful.

Table 4 shows that in the UK there is a much wider variety of performance targets/measures being used than in Ireland, with each of the four recommended 
HM Treasury categories (1992) being availed of. Although not shown in Table 4, all UK organisations reported at least one target and related measure in the quality of service and efficiency categories (with many reporting several, particularly with respect to quality of service), as well as reporting at least one volume of output measure (with most having at least one volume of output target as well). With respect to financial performance, most UK organisations disclosed at least one measure, although there were limited numbers of targets in this category. By contrast, the range of targets disclosed by Irish organisations was quite limited, with the vast majority being related to quality of service (albeit, as seen in Table 3, most Irish organisations disclosed no targets at all). There were no financial performance, volume of output or efficiency targets disclosed. In the case of measures of performance, 53 per cent of the measures ( 46 out of a total of 86 ) being used by Irish organisations were related to quality of service (largely aligning with the stated targets), with most of the remainder being volume of output measures (although, given that there were no volume of output targets, these were unrelated to any target). In Ireland there were virtually no financial performance and efficiency measures disclosed.

\section{ANALYSIS AND DISCUSSION}

It is suggested that performance measurement in the public sector has two main objectives. Firstly, organisations provide a basis for better management by setting targets for performance and by measuring achievements against these targets. The rational management literature and goal setting theory suggests that this gives direction to activities and provides a basis for evaluating the organisation's performance. Overall, it is argued that such an approach is a necessary basis for performance improvement. Secondly, the provision of performance information enables the organisation to discharge accountability. Accountability, and in particular accountability for performance, is especially important for public sector organisations as they seek to justify public funding and counter criticisms that they are inefficient and ineffective. These themes are a leitmotif in a range of UK and Irish government publications.

The empirical research in this paper indicates that in Ireland there is a substantial gap between the rhetoric contained in official government publications relating to the importance of performance measurement and management and its actual impact in Irish public sector organisations. A significant proportion of Irish public sector agencies disclose limited amounts of performance information in their annual reports. For example, only 3 out of 10 Irish organisations studied highlighted any targets. The research made no attempt to judge the appropriateness of particular targets and measures, nor is it necessarily the case that the production of more measures is a good thing. Indeed, it may be that in some areas of the public sector there is a danger of producing too many, unfocused and low-level, performance measures and targets and this can lead to confusion (Lapsley, 1996). Nevertheless, given the unambiguous statement in Irish government publications that public sector organisations should (and will) provide such 
Hyndman \& McGeough

information, the lack of reporting in Ireland is indicative of weak accountability. Readers of annual reports will have difficulty judging both efficiency (where inputs and outputs are compared) and effectiveness (where targets are compared to actual performance). As a consequence there will be less pressure on management to improve performance (a state of affairs perhaps not unwelcomed by some managers in the public sector). With respect to the UK organisations, there is a much greater proliferation of performance measures and targets, and these targets and measures are used as a basis for discharging accountability.

In relation to planning and control, as part of NPM, there is an increased emphasis on quantification per se, specifically in the context of a highly rational model of management behaviour, which has been influenced greatly by traditional functional studies of management processes. The argument is that public sector organisations should develop targets related to their planned performance and these will give direction to their activities and provide a basis for evaluating whether they have been effective and efficient. Overall, well-set targets, used effectively, will provide the foundation for performance improvement. While this research focuses on the discharge of accountability by public sector organisations through the medium of the annual report, it also suggests that performance information is lacking in the planning and control systems of public sector organisations (particularly in Ireland). If performance targets are a sine qua non for performance improvement (a line of reasoning used in rational management literature, goal setting theory and official government publications), a lack of target setting (in terms of numbers of targets or breadth of target coverage) will result in reduced performance. This is perhaps a major concern for those pushing for such reform in the Irish public sector.

To an extent, it is perhaps unsurprising that there is such a gap between the UK and Ireland in terms of implementing performance measurement and performance management systems (a key aspect of the NPM agenda). Although there are strong historical, cultural and economic links between the two countries, earlier international comparisons of the adoption of NPM reforms indicate that some countries embrace such reforms more intensely than others. Hood (1995) has suggested that the UK has been a high intensity adopter, compared to Ireland (a medium intensity adopter). Given this, the later and, to date, less intense adoption of a performance measurement framework in the Irish public sector is possibly to be expected. While the UK NPM agenda accelerated in the 1970s and 1980s, a period of economic difficulty in both Ireland and the UK, evidence of any significant impact of NPM reforms in Ireland is not available until well into the 1990s. Perhaps a crucial difference was that of political and ideological drive. In 1979 the Conservative party came to power in the UK, under Margaret Thatcher, and this heralded a major shift in the perceived role of the state in a modern Western society. Flynn (1997) and Chow, Humphrey and Miller (2005) argue that the Conservative government had a strong belief in reducing the role of the state, cutting public expenditure, learning from the private sector and placing greater emphasis on individuals taking more responsibility for themselves. This set the background against which many of the NPM reforms were introduced. In contrast, 
Ireland, possibly because of a more collectivist culture than the UK in terms of both politics and social issues, did not experience such a shift in public policy. A lack of strong political ideology in Ireland, coupled with an electoral system that often resulted in coalition governments (rather than a majoritarian government as was generally the situation in the UK), reinforced a more reflective, gradualist approach. Therefore, despite severe economic difficulties in Ireland, the approach adopted by Irish governments of various hues emphasised the importance of partnership and more consensual decision making in the public sector. Such is unlikely to lead to radical and speedy shifts in public policy, hence the results of the empirical research reported in this paper.

Nonetheless it is possibly of concern to some policy makers in the Irish public sector that there is a major disparity between the arguments relating to the importance of performance measurement and performance management (as outlined in official Irish government publications) and the impact of such rhetoric. A recent OECD report (2008) on public sector reform in Ireland may perhaps give renewed purpose to the SMI process and result in performance measurement and management assuming a more central role in the public sector. Or, given the more consensual approach adopted in Ireland and the lack of evidence of significant political will to drive change, conceivably radical transformation is unlikely and a gradualist, ad-hoc, cherry-picking, reflective process is more probable with respect to performance measurement specifically and a wide range of NPM reforms generally. Given the less than conclusive evidence to date that NPM reforms lead to better and more accountable government (Olson et al., 1998), perhaps the Irish approach is to be commended.

\section{NOTES}

1 Hood (1991) suggested that NPM is a convenient, though rather loose, term that is shorthand for a set of broadly similar administrative doctrines that dominated the reform agenda in the public sector in many OECD countries from the late 1970s. Moreover, he identifies the main themes of NPM as being 'the idea of a shift in emphasis from policy making to management skills, from a stress on process to a stress on output, from orderly hierarchies to an intendedly more competitive basis for providing public services, from fixed to variable pay and from a uniform and inclusive public service to a variant structure with more emphasis on contract provision' (Hood, 1995, p. 95).

2 An alternative view, as presented by Flynn and Strehl (1996), suggests a key influence on the pace of NPM implementation is the nature of political opinion at national level. They argue the use of market mechanisms for service delivery, an element of NPM reforms, requires an ideological commitment that is likely to be stronger among conservatives than socialists or social democrats. However, they do accept that there are exceptions to this.

3 PSAs describe what a department will deliver in the form of measurable targets, over the public expenditure review period, in return for its budget. 
Hyndman \& McGeough

APPENDIX I: AGENCIES/UNITS (ORGANISATIONS) INCLUDED IN THE EMPIRICAL ANALYSIS (PLUS DATE OF ANNUAL REPORT)

\begin{tabular}{ll}
\hline UK & Ireland \\
\hline Land Registry (2005/2006) & Land Registry (2005) \\
Ordnance Survey (2005/2006) & Ordnance Survey (2005) \\
UK Passport Service (2005/2006) & $\begin{array}{l}\text { Department of Foreign Affairs (2006) } \\
\text { Maritime Safety and Environment (Department } \\
\text { of Communications, Marine and Natural } \\
\text { Resources (2005)) }\end{array}$ \\
Marine Fisheries Agency (2005/2006) & $\begin{array}{l}\text { Marine Resource Management (Department of } \\
\text { Communications, Marine and Natural }\end{array}$ \\
Patent Office (2005/2006) & Resources (2005)) \\
Companies House (2005/2006) & $\begin{array}{l}\text { Eepartment of Enterprise, Trade and } \\
\text { Her Majesty's Courts Service (2005/2006) }\end{array}$ \\
Insolvency Service (2005/2006) & $\begin{array}{l}\text { Companies Registration Office (2005) } \\
\text { Courts Service (2005) }\end{array}$ \\
Employment Tribunals Service (2005/2006) & Enforcement (2006) \\
\hline
\end{tabular}

\section{APPENDIX 2: LENGTH (INCLUDING APPENDICES) OF ANNUAL REPORTS}

\begin{tabular}{lll}
\hline UK & & Ireland \\
& Number of pages & Number of pages \\
\hline
\end{tabular}

Stand-Alone Agencies (UK/Ireland)

Land Registry/Land Registry

$128 \quad 27$

Ordnance Survey/Ordnance Survey

Companies House/Companies Registration Office

Courts Service/Courts Service

Insolvency Service/Office of the Director of

Corporate Enforcement

Employment Tribunals Service/Employment

Appeals Tribunal

Average number of pages for matched organisations I-6

UK Stand-Alone Agencies/Irish Subsections of Department

UK Passport Service/Department of Foreign Affairs*

Maritime and Coastguard Agency/Maritime Safety and Environment**

Maritime Fisheries Agency/Marine Resource Management**

Patent Office/Department of Enterprise, Trade and Employment**

Average number of pages for matched organisations 7-10

$\begin{array}{ll}91 & 3 \\ 151 & 9 \\ 72 & 9 \\ 60 & 1 \\ 94 & \\ 84 & 6\end{array}$

Average number of pages for all 10 matched organisations $\quad 84 \quad 34$

*Consular and Passport section only

**Relevant sections from the annual report, excluding the annual accounts 
NPM and Performance Measurement

\section{REFERENCES}

Accounting Standards Committee (ASC) (1975). The Corporate Report, London: ASC.

Argenti, J. (1980). Practical Corporate Planning, London: George Allen \& Unwin.

Barnes, C. and Gill, D. (2000). Declining Government Performance? Why Citizens Don't Trust Government, working paper, Wellington: State Services Commission.

Bates, J. (1993). Managing Value for Money in the Public Sector, London: Chapman \& Hall.

Boston, J. (1991). Reshaping the State: New Zealand's Bureaucratic Revolution, Auckland: Oxford University Press.

Bovaird, T. and Loffler, E. (eds) (2003). Public Management and Governance, London: Routledge.

Boyne, G. and Law, J. (1991). Accountability and Local Authority Annual Reports: The Case of the Welsh District Councils, Financial Accountability \& Management, Vol. 7, No. 4, pp. 179-194.

Broadbent, J. and Guthrie, J. (1992). Changes in the Public Sector: A Review of 'Alternative' Accounting Research, Accounting, Auditing \& Accountability Journal, Vol. 5, No. 2, pp. 3-31.

Broadbent, J. and Laughlin, R. (2006). Performance Management Systems: A Conceptual Model and an Analysis of the Development and Intensification of 'New Public Management' in the UK, research paper, London: Roehampton University.

Carroll, J. (1995). The Rhetoric of Reform and Political Reality in the National Performance Review, Public Administration Review, May-June, Vol. 55, No. 3, pp. 302-312.

Chow, D., Humphrey, C. and Miller, P. (2005). Financial Management in the UK Public Sector, in J. Guthrie, C. Humphrey, L.R. Jones and O. Olson (eds), International Public Financial Management Reform: Historical Development, Current Issues and Controversies, Greenwich, CT: Information Age Publishing.

Connolly, C. and Hyndman, N. (2003). Performance Reporting by UK Charities: Approaches, Difficulties and Current Practice, Edinburgh: The Institute of Chartered Accountants of Scotland.

Department of Finance (2004a). Business Planning Guidelines and Sample Templates, Dublin: Department of Finance.

Department of Finance (2004b). Management Information Framework: Report on Performance Indicators, Dublin: Department of Finance.

Department of Finance (2006a). Management Information Framework: Performance Indicators A Users' Guide, Dublin: Department of Finance.

Department of Finance (2006b). Ireland - Stability Programme Update, Dublin: Department of Finance.

Department of the Taoiseach (1996). Delivering Better Government, Dublin: Department of the Taoiseach.

Department of the Taoiseach (2004). Guidelines for Secretaries General and Heads of Office on the Preparation of Strategy Statements, Dublin: Department of the Taoiseach.

Dobell, R. and Zussman, D. (1981). An Evaluation System for Government: If Politics Is Theatre, Then Evaluation Is (Mostly) Art, Canadian Public Administration, Vol. 24, No. 3, pp. 404-427.

Drucker, P. (1954). The Practice of Management, New York, NY: Harper and Row.

Edwards, M. and Hulme, D. (1995). Non-Governmental Organisations: Performance and Accountability, London: Earthscan Publications.

Expenditure Review Central Steering Committee (2005). Report of the Pilot Project on Resource Allocation, Business Planning and Performance Measurement, Dublin: Department of Finance. 
Hyndman \& McGeough

Flynn, N. (1997). Public Sector Management, London: Prentice Hall.

Flynn, N. and Strehl, F. (eds) (1996). Public Sector Management in Europe, London: Prentice Hall.

Fuller, D. and Roffey, B. (1993). Improving Public Sector Accountability and Strategic Decision Making, Australian Journal of Public Administration, Vol. 52, No. 2, pp. 149-163.

Gibson, J.L. (1978). Performance Indicators in the Court System, in S. Greer, R. Hedlund and J.L. Gibson (eds), Accountability in Urban Society: Public Agencies Under Fire, London: Sage Publications.

Government Accounting Standards Board (GASB) (1987). Concepts Statement No. 1: Objectives of Financial Reporting, Stamford: GASB.

Government of Ireland (1997). Public Service Management Act, No. 27 of 1997, Dublin: Stationery Office.

Gray, R. (1983). Accounting, Financial Reporting and Not-For-Profit Organisations, AUTA Review, Vol. 15, No. 1, pp. 3-23.

Hedlund, R.D and Hamm, K.E. (1978). Accountability and Political Institutions, in S. Greer, R. Hedlund and J.L. Gibson (eds), Accountability in Urban Society: Public Agencies under Fire, London: Sage Publications.

HM Treasury (1992). Executive Agencies: A Guide to Setting Targets and Measuring Performance, London: Stationery Office.

HM Treasury (2001). Choosing the Right Fabric: A Framework for Performance Information, London: HM Treasury.

Hofstede, G. (1981). Management Control of Public and Not-For-Profit Activities, Accounting, Organizations and Society, Vol. 3, No. 3, pp. 193-221.

Hofstede, G. (2001). Culture's Consequences: Comparing Values, Behaviors, Institutions and Organizations Across Nations, Thousand Oaks, CA: Sage Publications.

Hood, C. (1991). A Public Management for All Seasons, Public Administration, Vol. 69, No. 1, Spring, pp. 3-19.

Hood, C. (1995). The 'New Public Management' in the 1980s: Variations on a Theme, Accounting, Organizations and Society, Vol. 20, Nos. 2-3, pp. 93-109.

Hopwood, A.G. (1985). Accounting and the Domain of the Public: Some Observations on Current Developments, University of Leeds: The Price Waterhouse Public Lecture on Accounting.

Hyndman, N. (1990). Charity Accounting: An Empirical Study of the Information Needs of Contributors to UK Fund Raising Charities, Financial Accountability and Management, Vol. 6, No. 4, pp. 295-307.

Hyndman, N. and Anderson, R. (1992). External Reporting by UK Public Sector Agencies: An Analysis of Accountability, Irish Accounting and Finance Association Proceedings, pp. 51-65.

Hyndman, N. and Anderson, R. (1997). The Use of Performance Information in External Reporting and Internal Planning: A Study of Executive Agencies, research report, London: The Association of Chartered Certified Accountants.

Hyndman, N. and Eden, R. (2000). A Study of the Co-Ordination of Mission, Objectives and Targets in UK Executive Agencies, Management Accounting Research, Vol. 11, No. 2, pp. 175-191.

Hyndman, N. and Eden, R. (2001). A Research Study of the Co-Ordination of Mission Statements, Objectives and Targets in UK Executive Agencies, London: Chartered Institute of Management Accountants.

Jackson, P. (1988). The Management of Performance in the Public Sector, Public Money $\mathcal{E}$ Management, Vol. 8, No. 4, Winter, pp. 11-16.

Lane, J.E. (1997). Public Sector Reform: Rationale, Trends and Problems, London: Sage Publications. 
Lapsley, I. (1996). Reflections on Performance Measurement in the Public Sector, in I. Lapsley and F. Mitchell (eds), Accounting and Performance Management: Issues in the Private and Public Sectors, London: Paul Chapman.

Laughlin, R.C. (1990). A Model of Financial Accountability and the Church of England, Financial Accountability \& Management, Vol. 6, No. 2, pp. 93-114.

Locke, E.A. (1968). Toward a Theory of Task Motivation and Incentives, Organizational Behavior and Performance, Vol. 3, pp. 157-189.

Locke, E.A. and Latham, G.P. (1990). A Theory of Goal Setting and Task Motivation, Englewood Cliffs, NJ: Prentice Hall.

Locke, E.A. and Latham, G.P. (2002). Building a Practically Useful Theory of Goal Setting and Task Motivation: A 35-Year Odyssey, American Psychologist, Vol. 57, No. 9, pp. 705-717.

Matheson, A. and Kwon, H. (2003). Public Management in Flux, in T. Bovaird and E. Loffler (eds), Public Management and Governance, London: Routledge.

Mayston, D. (1985). Non-Profit Performance Indicators in the Public Sector, Financial Accountability \& Management, Vol. 1, No. 1, pp. 51-74.

McSweeney, B. (1988). Accounting for the Audit Commission, The Political Quarterly, Vol. 59, No. 1, pp. 28-43.

Miah, N.Z. (1991). Attempts at Developing a Conceptual Framework for Public Sector Accounting in New Zealand, Financial Accountability \& Management, Vol. 7, No. 2, pp. 83-97.

Miller, P. and O'Leary, T. (1987). Accounting and the Construction of the Governable Person, Accounting, Organizations and Society, Vol. 12, No. 3, pp. 235-266.

Olson, O., Guthrie, J. and Humphrey, C. (1998). Global Warning: Debating International Developments in New Public Financial Management, Oslo: Cappelen Akademisk Forlag AS.

Organisation for Economic and Cultural Development (OECD) (2008). Ireland: Towards an Integrated Public Service, OECD Public Management Review, Paris: OECD

Pathfinder Project (2003). Guidance on Outcome Focused Management - Building Block 1: Identifying Outcomes, Wellington: Pathfinder Project.

Pollitt, C. (1993). Managerialism and the Public Services, Second Edition, Oxford: Blackwell Publishers.

Pollitt, C. and Bouckaert, G. (2004). Public Management Reform: A Comparative Analysis, Oxford: Oxford University Press.

Public Administration Select Committee (2003). Minutes of Evidence, London: HM Government.

Sanderson, I. (1996). Evaluation, Learning and the Effectiveness of Public Services, International Journal of Public Sector Management, Vol. 9, Nos. 5-6, pp. 90-106.

Sharifi, S. and Bovaird, T. (1995). The Financial Management Initiative in the UK Public Sector: The Symbolic Role of Performance Reporting, International Journal of Public Administration, Vol. 18, Nos. 2-3, pp. 467-490.

Smith, P. (1993). Outcome-Related Performance Indicators and Organisational Control in the Public Sector, in J. Halloway, J. Lewis and J. Mallory (eds), Performance Measurement and Evaluation, London: Sage Publications.

State Services Commission (1999). Improving Accountability: Setting the Scene, Wellington: New Zealand Government.

Stewart, J. (1984). The Role of Information in Public Accountability, in A.G. Hopwood and C. Tomkins (eds), Issues in Public Sector Accounting, Abingdon: Philip Allan Publishers.

Thompson, G.D. (1995). Problems with Service Performance Reporting: The Case of Public Art Galleries, Financial Accountability \& Management, Vol. 11, No. 4, pp. 337-355.

Zifcak, S. (1994). New Managerialism: Administrative Reform in Whitehall and Canberra, Buckingham: Open University Press. 